\title{
La mujer puertorriqueña y el trabajo, siglo XVIII
}

\author{
Ángel López Cantos \\ Departamento de Historia de América \\ Facultad de Geografía e Historia \\ Universidad de Sevilla
}

\begin{abstract}
Las notas que siguen son únicamente un intento de aproximarnos al mundo laboral de la mujer puertorriqueña del siglo XVIII. Decimos un intento porque en ello se queda, ya que las fuentes para su reconstrucción son pobres y escasas y, además, proporcionadas por los hombres y dentro de una documentación de origen oficial. Asimismo, no contamos con escritos redactados por las propias mujeres. Con intención de informar sobre la vida y obras de aquellos habitantes sólo disponemos de un crónica titulada: Historia geográfica, civil y natural de la isla de San Juan de Puerto Rico, escrita por el fraile benedictino Íñigo Abbad y Lasierra, que vivió en San Juan durante los últimos años de esa centuria. En los comentarios personales que hace a todas las noticias, nos muestra el mayor de los desprecios hacia los isleños, pero donde el desdén se aproxima al rencor, es al referirse a las mujeres y, por supuesto, también cuando habla del trabajo de ellas. Pese a estos inconvenientes, en medio de un mar de documentos, hemos encontrado noticias sueltas con las que acercarnos, aunque sea de puntillas, a lo que debió ser el mundo laboral de la mujer boricua durante el XVIII.
\end{abstract}

\section{Actitud ante el trabajo: fábulas y realidades}

A lo largo de estas notas irán brotando de manera pertinaz las palabras "negras" y "mulatas"; "mujeres de color", libres o esclavas. Su importancia dentro del contexto social puertorriqueño quedará reflejada en las páginas siguientes. Por lo tanto es necesario determinar quiénes fueron en la práctica los sujetos activos del mundo del trabajo femenino en Puerto Rico. Para ello debemos presentar el armazón del funcionamiento de la sociedad puertorriqueña.

La sociedad isleña era muy heterogénea. La diversidad de sus componentes ocasionó que tuviera unas características propias que la hacían diferente a la española del mismo período, pero de la que tomaba muchos roles a causa de un origen común. Hacer una división esquemática no es tarea fácil. Los valores que lleva España a América están imbricados con los conceptos de la sociedad medieval: en ellos se enaltecía todo lo relacionado con el honor, unido, ante todo, con el servicio militar y la nobleza y combinado con el desprecio al trabajo vil.

La pauta para la calificación de los grupos sociales en Puerto Rico se basó más en los aspectos étnicos que en la situación económica. Las elites 
se autodenominaron españolas. Comprendían a los peninsulares y a los criollos blancos o tenidos por tales: los conocidos por "hombres honrados." El segundo escalón lo ocupaban los pardos y morenos libres. La base de la pirámide social la constituían los esclavos, mulatos y negros.

Los "hombres honrados" estaban destinados a toda y cada una de las complejas labores del gobierno de la república y al ejercicio militar. Las ocupaciones manuales y aun comerciales se consideraban indignas de su clase. El trabajo vil le estaba encomendado a los hombres de color. Los libres representaban a los profesionales cualificados: los artesanos. Los siervos se dedicaban casi exclusivamente a aquellos menesteres donde privaba la fuerza y no se precisaba de grandes conocimientos técnicos. ${ }^{1}$

Estos breves y lineales apuntes determinan quién fue el sujeto real de este análisis: la mujer de color, libre o esclava y, en mucha menor medida, la blanca.

En el año 1703 se remite un informe a la Corona desde San Germán en el que se le exponen las necesidades que padece la Villa en particular y toda la Isla en general. Entre las más acuciantes estaba la falta de población. Para remediar, en parte, esta situación se solicitó que enviasen habitantes desde las islas Canarias. Con esto no sólo se pretendía conseguir un objetivo, sino también aprovecharse de los conocimientos propios de las mujeres de aquella época. Se piensa que

“... puedan ser de mucho útil a las de San Germán y San Juan, enseñándoles a hilar y tejer lino, cáñamo, algodón y cadillo, [una especie de hierva fibrosa que se cría en los trigos y se podía tejer] y que será así lo prueba la misma esterilidad que hubo en Caracas." 2

Se puede pensar que la artesanía entre las isleñas, según la afirmación anterior, había casi desaparecido y que su resurgimiento posterior fue debido a la llegada de los canarios a Puerto Rico. Nada más lejos de la realidad.

La demanda de canarios no tuvo efecto inmediato, pues hasta 1720 no se produjo el arribo del primer contingente de isleños. Durante la década de los años veinte desembarcaron ocho expediciones con un total de 882 individuos. Este es el único período de Puerto Rico en que se tiene constancia de la llegada sistemática de canarios.

1 López Cantos, Ángel: "La sociedad de Puerto Rico en el siglo XVIII", Anales, Nueva serie, vol. 1, núm. 1 y 2, San Germán, 1985, págs. 7-29.

2 Archivo General de Indias (en adelante, AGI), Santo Domingo, 560. Informe de Sebastián Fernández de Miraval al rey. San Germán, 1703. 
Los resultados no pudieron ser más negativos para la demografía isleña ni más catastróficos para los emigrantes. En 1728 el gobernador Juan Antonio Mendizábal comunicaba a la corte que acababa de recibir una remesa de treinta y dos familias. Después de afirmar que todos habían llegado bien, escribe que permanecen

"en sanidad y robustez como los naturales, pues con la política de mantenerles den-
tro de la ciudad el tiempo que parece conveniente, sin salir a los campos, aunque les
ha dado alguna chapetonada asistida con caridad se han hecho a este temperamento.
Discurro que siguiendo el mismo método con los que llegaron hasta ahora y en ade-
lante vinieren, no experimentarán la infelicidad de los que llegaron en tiempo de mi
antecesor, pues de quinientas personas que se componían sólo se hallan vivas cuatro
o cinco, cuya desgracia padecieron por la impráctica de haberles internado en las
montañas sin dejarles reposar siquiera quince días entre la ciudad, hacerse a las aguas,
aires y bastimentos, sin faltarles las curaciones."”

Esta realidad limitó el posible aprendizaje. También lo restringió la norma que en aquellos momentos se practicaba con los recién llegados a la Isla. La política que se seguía era destinarlos a todos a un lugar concreto con el fin de que fundaran una población. Todos permanecían juntos sin mezclarse con los puertorriqueños. ${ }^{4}$ Difícilmente, por tanto, las mujeres canarias pudieron ser monitoras de las puertorriqueñas. Asimismo, no se puede olvidar la extracción social de algunas de ellas. No todas fueron madres de familia honestas y hacendosas.

En 1678 se ordena que todos los barcos canarios que desearan comerciar con las islas de Barlovento tenían la obligación de transportar cinco familias hacia aquellos lugares por cada cien toneladas de mercancías que cargaren. Las familias debían estar compuestas por cinco personas. ${ }^{5}$ Esto originó, en no pocos casos, que los interesados en este comercio procuraran el permiso a cambio de reunir las familias que precisaban, aunque sus individuos no estuvieran unidos por el vínculo de sangre. No tuvieron empacho en formarlas con personas dispares y, en algunas ocasiones, del mundo marginal. Con esto creyeron que cumplían su parte en el acuerdo y que las autoridades de Puerto Rico no captarían el engaño. No fue así.

3 López Cantos, Ángel: "La emigración canaria a Puerto Rico en el siglo XVIII", Actas del IV Coloquio de Historia Canario-Americana, Las Palmas de Gran Canaria, 1984, págs. 91-114.

4 Gil Bermejo, Juana: "La primera fundación de Humacao", Revista del Instituto de Cultura Puertorriquẽ̃a, núm. 22, San Juan de Puerto Rico, enero-marzo, 1964, págs. 37-40.

5 AGI, Santo Domingo, 465. Certificación de los oficiales reales de Puerto Rico. Puerto Rico, 12 de octubre de 1721. 
El gobernador Francisco Danío Granados se quejó al rey y le manifestó que en las expediciones había arribado el número exacto de familias que se determinaban y cada una de cinco personas, pero en realidad no eran familias, sino grupos de personas de cinco individuos. Entre las mujeres venían algunas rameras. Y así se lo notificó:

"Que han venido en las primeras veinte familias como en las treinta consecutivas que arribaron por el presente año, las que han hecho poner en estado pues de esto sólo resultan inconvenientes."

La solución que se propiciaba para reeducar a la mujer puertorriqueña en el hilado y tejido no pudo venir de las canarias por las razones más arriba expuestas. Fueron pocas las que sobrevivieron en su nueva patria y las que lo hicieron, a causa de un sistema de población determinado, debían habitar los primeros años en lugares apartados y lejos de los isleños y, por consiguiente, se produjo un escaso trato con las nativas. Y llegó a darse el caso paradójico de que algunas canarias, por motivos de su anterior vida, tuvieron que ser reeducadas.

La falta de práctica de la mujer puertorriqueña en esas labores, sin duda, debió existir. No obstante, no fueron las canarias, como se solicitaba, las que enseñaron a las de Puerto Rico, sino que ellas mismas mantuvieron los conocimientos que transmitieron de generación en generación.

En el último tercio del siglo XVIII parece ser que la situación no había cambiado. Abbad y Lasierra nos describe el comportamiento laboral de las isleñas con estas palabras:

"El trabajo de las mujeres es casi ninguno: ni hilan, ni hacen medias, cosen muy poco y pasan la vida haciendo cigarros y fumando en las hamacas; las faenas de la casa corren por cuenta de las esclavas."”

Como casi siempre sus observaciones son superficiales, sin adentrarse en las posibles razones que las motivaban. En ellas se trasluce un inequívoco desamor hacia los puertorriqueños. Además, se da una contradicción manifiesta cuando asevera que "... las faenas de la casa corren por cuenta de las esclavas.” ¿Acaso éstas no eran mujeres? ¿O es que el benedictino

6 AGI, Santo Domingo, 2297. El gobernador Francisco Danío Granados al rey. Puerto Rico, 20 de junio de 1723 .

7 Abbad y Lasierra, Íñigo: Historia geográfica, civil y natural de la Isla de San Juan de Puerto Rico, México, 1959, págs. 187-188. 
no las tenía por tales? Un hecho quedó meridianamente manifiesto. Al menos, las siervas sí conocían el arte de hilar, hacer calceta, coser y todas aquellas tareas propias del quehacer doméstico. La matización hay que considerarla muy importante, ya que nos presta una pista de gran trascendencia a la hora de analizar este apartado. En efecto, el mundo del trabajo estuvo casi en manos de las esclavas y de algunas negras y mulatas libres, y no todas, ya que la mujer de color, por lo general, si poseía siervas actuaba de igual forma que las blancas o consideradas por tales.

De la escueta lectura del testimonio anterior es factible entrever que la mayoría de las isleñas eran perezosas. No se dedicaban a aquellas ocupaciones propias y que la sociedad tradicionalmente les había encomendado en razón de su sexo. No se afirma en el texto que no supieran realizarlas, sino que no las practicaban. Sin ánimo de justificar ninguna actitud, es ineludible puntualizar esas dos notas: desidia e ignorancia.

Al hablar de la negligencia hay que resaltar que, asimismo, se podía aplicar al hombre. La ociosidad, la desidia, la pereza, la dejadez fueron notas con las que constantemente los contemporáneos describieron a la sociedad isleña. Muchas personas opinaron sobre el tema y la mayoría de manera superficial, sin profundizar, ni siquiera intentar comprender las motivaciones que daban pie a que los isleños fueran ociosos y perezosos. En la documentación de la época se puede encontrar un rosario de citas a este respecto. Un gobernador afirmó: "Estos naturales y vecinos han vivido de tiempo inmemorial en el mayor ocio." Otro pensaba de la siguiente manera: "Los naturales del país son muy desidiosos, aunque se estimulen." Podíamos seguir presentando testimonios de este tipo y en todos coincide la idea fundamental: la dejadez y la desidia. Para Lasierra la causa se encuentra en la riqueza de la tierra y la facilidad en proporcionar los frutos. Esto originó la pereza y, por ende, la frugalidad. Casi todos se quedan en la superficie del problema, sin ahondar en él. Según ellos, el isleño con poco esfuerzo podía obtener lo necesario para la vida. Lo tenía todo al alcance, como si del Paraíso se tratara. Contaba con tierra fértil, clima amable y, por tanto, ¿qué utilidad conseguía con el esfuerzo de cultivarla, si los frutos surgían por doquier, como por generación espontánea?

Debieron existir unos motivos más trascendentales y que, por supuesto, otro observador más sutil los hubiera atisbado. Nos presentan la vida de los puertorriqueños como la quintaesencia de la sencillez. Nada más falso. Si ojeamos los embargos de los bienes muebles que la administración realizó a no pocos isleños acusados de cometer algún delito, quedamos sor- 
prendidos de las riquezas que algunos poseían en vestidos, joyas, enseres de todo tipo como muebles, cuadros, ropas de cama y mesa, etcétera. Luego, no se les podía tildar de ociosos y perezosos porque no deseaban nada más que aquello que podían conseguir con casi ningún esfuerzo. Su frugalidad no era tanta como se puede deducir de las afirmaciones del fraile benito.

Las razones debieron ser, opinamos, bastante más profundas. Hubo varios coetáneos que profirieron unas observaciones acertadas. Según ellos todo esfuerzo laboral era inútil. Perderían trabajo, fatigas y el poco dinero que poseían, ya que los objetos de sus desvelos, los productos conseguidos en sus fértiles tierras no tendrían salida, no podrían comercializarse por la infraestructura viaria, que en la práctica no existía y encarecería los costos de producción de forma excesiva. Esto se agravaba con el sistema de puerto único, San Juan, para el tráfico mercantil exterior. Y si en el mejor de los casos llegaban los "frutos de la tierra" a la capital de la Isla, después de sufrir multitud de peripecias y penalidades, en muchas ocasiones se encontraban con un obstáculo insalvable: la falta de embarcaciones que los sacaran del país. Ante tal realidad incuestionable, de bien poco les hubiera servido a los indolentes puertorriqueños el romper su apatía y dedicarse a la producción de bienes para la exportación. Nadie trabaja por el simple placer de trabajar. ${ }^{8}$

\section{La mujer y las tareas del hogar}

No es de extrañar ante lo expuesto que, asimismo, se tildara a la isleña de perezosa. Como mujer tenía encomendados los quehaceres propios del hogar. Y si la desidia del hombre estuvo motivada por razones de origen económico, la atribuida a su compañera participó de idénticas connotaciones.

La pobreza, en general, era el denominador común más extendido. La falta de medios económicos se refleja, como era de suponer, en las viviendas que poseían la mayoría de los isleños. Eran muy simples, por no decir primitivas. La mayoría estaban construidas de "madera y tablas cobijadas de yaguas", o "madera y yaguas y atadas con juncos", o “... con bejucos."

8 López Cantos, Ángel: "Notas para una aproximación al carácter de los puertorriqueños (Siglo XVIII)", Cruz Ansata, vol. 10, Bayamón, 1987, págs. 116-121. 
En pocas de éstas utilizaban los clavos para fijar las maderas. Por lo general, las habitaciones quedaban reducidas a "un soberado", "la sala de afuera" y "el aposento." Una cocina adosada a la casa y que se comunicara con ella era un lujo que muy pocos disfrutaban. Comúnmente estaban separadas de la vivienda, al aire libre, por lo general debajo de un árbol y se reducía a un fuego donde se preparaban los alimentos. Con ello se alejaba el peligro de un probable incendio.

La estructura de las casas comunes quedaba reducida a un porche, donde se hacía prácticamente la vida; de una sala que servía de almacén y despensa y de noche, al colgar las hamacas, se transformaba en dormitorio de hijos y esclavos, y un aposento interior, dormitorio permanente de los padres a la vez que almacén de otros usos, como depósito de bastimentos y ropas. La mayor cantidad de moradores no incrementaba el número de habitaciones. El sacristán de Ponce, Francisco Lamboy, era padre de nueve hijos y junto con su mujer vivían en una casa de dos habitaciones. ${ }^{9}$

Esta realidad quedó reflejada en los informes de los obispos. En su obligación de velar por la moral y las buenas costumbres de sus feligreses vieron el peligro que encerraban habitáculos tan menguados. El prelado Pedro de la Concepción Urtiaga afirmaba que la causa de que se dieran "adulterios, incestos y concubinatos es por vivir amontonados como brutos en estrechas viviendas." 10

El hacinamiento era, por lo general, común a todas las familias. Para aprovechar el espacio mejor o por simple necesidad, los hijos, aunque fueran de distinto sexo y aun en edades crecidas, compartían una misma cama. Igual ocurría entre la servidumbre. Por estas circunstancias no era extraño que los apareamientos esporádicos o permanentes, al margen de las leyes y las costumbres, constituyeran moneda común en los hogares de no pocos puertorriqueños. ${ }^{11}$

Las casas de las elites se diferenciaban más por los materiales con que estaban construidas, "de piedra y tejas" o "de madera y tejas", que por el

9 AGI, Santo Domingo, 561. Embargo de los bienes de Francisco Lamboy. Ponce, 16 de enero de 1701 .

10 AGI, Santo Domigo, 880. Real cédula al obispo de Puerto Rico, Pedro de la Concepción Urtiaga. Madrid, 13 de octubre de 1713.

11 Visita canónica del obispo Juan Bautista Zengotita a Puerto Rico. Puerto Rico, 1796-1799. En el punto sexto de las resultas de la visita, entre otras cosas ordena: "Asimismo, dispongan los padres de familia que sus hijos llegados a tener algún conocimiento no duerman en una misma cama con las hijas, lo que igualmente observarán respecto a los demás domésticos, en cuyo particular encargamos a los tenientes a guerra con el desvelo y cuidado coadyuven a estos santos fines." 
número de habitaciones. ${ }^{12}$ Las plantas de unas y otras solían ser, por lo común, muy parecidas. ${ }^{13}$

Después de analizar el entorno doméstico y las limitaciones casi inverosímiles del espacio en que se desenvolvían las familias puertorriqueñas, es preciso reconocer que el esfuerzo físico que la isleña tuvo que dedicar para mantener correctamente en orden sus hogares no podía ser muy grande. Las faenas de la casa, su aseo y su organización con poco esfuerzo y tiempo estaban despachadas, dejándoles mucho tiempo libre. Pero culturalmente la mujer tenía encomendadas otras misiones: la preparación de los alimentos y la confección y arreglo de los vestidos.

No se pretende en este análisis estudiar los alimentos ni la dieta de los puertorriqueños del siglo XVIII. Queremos aproximarnos al esfuerzo que la isleña tuvo que realizar en el proceso de convertir los víveres en productos inmediatos de consumo para la familia. No hay que olvidar que muchos de los productos que tan generosamente proporcionaba la Isla no se podían consumir directamente: era necesaria una transformación y una posterior y complicada elaboración para su consumo.

Abbad y Lasierra, al tratar este punto, sigue insistiendo que las mujeres de Puerto Rico trabajaban poco. La abundancia de frutos, carnes, pescados y mariscos daban lugar a que pasasen "la vida regalada a su modo y cuasi sin ningún trabajo." ${ }^{14}$ Esta afirmación induce a crear en el ánimo del lector la imagen de que el hombre puertorriqueño sólo tenía que extender las manos y recoger lo que la naturaleza le ofrecía para su manutención y recreo. Todos los esfuerzos quedaban reducidos a un elemental acto de recolección. En efecto, los alimentos eran abundantes y de fácil obtención. El gobernador Miguel de Muesas escribió al secretario de Indias:

12 Los datos para la reconstrucción de las viviendas están tomados de los siguientes embargos existentes en el AGI. Santo Domingo, 543. Francisco Ribera. San Felipe de Arecibo, 23 de septiembre de 1700. Santo Domingo, 651. Blas de la Candelaria. Ponce, 16 de enero de 1701. Santo Domingo, 2367. Andrés Granados. Cayey, 26 de enero de 1784. Escribanía de Cámara, 120 B. De Pedro Rodríguez. Puerto Rico, 3 de diciembre de 1723. Escribanía de Cámara, 128 A. Juan Rodríguez Padilla. Cabo Rojo, 8 de agosto de 1709, y Nicolás de Ayala. San Germán, 22 de agosto de 1709.

13 En AGI. La casa del capitán Francisco Vicente Romero sólo tenía una sala principal y un aposento. Puerto Rico, 30 de enero de 1702. Santo Domingo, 551. La del fiscal de la real hacienda, un cuarto de estudio y una alcoba. Puerto Rico, 19 de septiembre de 1797. Santo Domingo, 2316. La de Antonio Carvajal y Benavides, "una sala principal", "un cuarto de adentro", "y un aposentillo que sirve de despensa." Puerto Rico, 28 de octubre de 1700. Escribanía de Cámara, 126 A. Y la del condestable Jerónimo Narro, una sala principal, un aposento y “un pequeño cuarto.” Puerto Rico, 17 de noviembre de 1707. Escribanía de Cámara, 140 A.

14 Abbad y Lasierra, Íñigo: "Viaje a la América", Boletín de la Academia Puertorriqueña de la Historia, edición facsímil, vol. V, núm. 18, San Juan, Puerto Rico, 1977, sin numerar. 
"Los víveres del país se hallan abundantes, ningún comestible falta. En la guarnición, cabildo, paisanaje y en todos reina la mayor tranquilidad." 15

Además de guisar, las isleñas estaban obligadas a llevar a cabo otras actividades destinadas a completar la dieta de su familia. La fabricación del pan casabe no era tarea fácil. Había que someter a la yuca a un complicado y laborioso proceso hasta obtener de ella un alimento sano y nutritivo. También era misión suya asar los plátanos, los hartones, otro sucedáneo del pan de trigo. A su incumbencia competía, asimismo, cuando la yuca y los plátanos faltaban por efecto de los huracanes o de las secas, echar mano de

"la raíz de la planta que llamaban marungüey, ésta la rallan, la dejan podrir y secar hasta que se puede hacer polvo como harina y de él hacen tortas y bollos que comen como pan."

Con "otra especie de plátanos más pequeños" conseguían un vinagre casero para condimentar los alimentos. ${ }^{16}$ Del jugo venenoso de la yuca, "después de hervirlo pierde su mala calidad y lo usan para salsa o sainete en las comidas de pescado." 17

En la dieta del isleño no sólo entraban frutos que se podían consumir directamente. El mismo Lasierra escribe que "su vianda se reduce a una olla de arroz o batatas, ñame, calabazas o todo junto." ${ }^{18}$ Estos alimentos los tenía que cocinar la mujer. Otro tanto ocurría cuando se trataba de las omnipresentes habichuelas o frijoles. ${ }^{19} \mathrm{Si}$ tal era la base de su diario yantar, la mujer puertorriqueña tuvo que cocinar todos los días y estos menesteres los debió ejercitar aun en aquellos años que las tormentas y huracanes arrasaban las cosechas y las circunstancias económicas por las que pasaba la familia no les favorecía. Gaspar González, vecino de Humacao, afirmó "que se ha estado alimentando de pan y carne más de año y medio." ${ }^{20} \mathrm{La}$ carne se consumía cocida o asada. El pan a que hace referencia el testimonio anterior procedía de la yuca. Ambos los aderezaba su mujer.

15 AGI, Santo Domingo, 2510. El gobernador Miguel de Muesas a Julián de Arriaga. Puerto Rico, 15 de mayo de 1771.

16 Abbad y Lasierra: "Viaje a...", s/n.

17 Abbad y Lasierra: Historia geográfica..., pág. 233.

18 Ibídem, pág. 186.

19 AGI, Santo Domingo, 2413. Representación del diputado de abastos Antonio de Córdova. Puerto Rico, 19 de agosto de 1793.

20 AGI, Escribanía de Cámara, 141 A. Confesión de Gaspar González ante el juez de residencia. Puerto Rico, 1 de enero de 1723. 
Estas labores domésticas tenían un inconveniente añadido. Las cocinas, como ya se ha apuntado, no existían en la práctica. En el mejor de los casos quedaban reducidas a un fogón, unos armarios y unas frasqueras. ${ }^{21}$ Lo habitual, en los bohíos y casas de "madera y yaguas", de "madera y tejas" o de "piedras y tejas" era que en las proximidades tuvieran un hogar al aire libre. En las casas de San Juan y San Germán se acondicionaban en los patios y en los huertos interiores y en el campo, junto a las viviendas. No le debió resultar a la puertorriqueña una ocupación agradable trabajar en tales condiciones. Es preciso cuestionar lo que afirmaba el fraile benedictino de que "pasaban la vida regalada a su modo y cuasi sin ningún trabajo." La preparación de los alimentos constituyó una actividad diaria y resultó bastante incómoda y dificultosa.

Además de las tareas propias del hogar, la mujer colaboró activamente en la elaboración del aguardiente romo o del ron..$^{22}$ Todas las haciendas poseían un pedazo de cañaveral, que dedicaban sólo a la producción del ron. ${ }^{23}$ Las ocupaciones agrícolas eran por lo general faenas de los hombres. El descañonar y triturar las cañas en los inevitables trapiches de tracción humana estaba encomendado a las mujeres, al igual que alimentar el fuego de las calderas de los alambiques. ${ }^{24}$ Con esta actividad intervino directamente en la economía familiar "por ser el ramo que con menos esfuerzo rinde más utilidad." ${ }^{25}$

"Yo — escribió un médico- en todo este referido tiempo de ocho años, siempre he visto usar con feliz suceso este expresado licor de aguardiente no sólo en los que han ejercitado alguna fatiga violenta y sudado lo han usado interiormente, sino también exteriormente dándose una frotación tibia universal, los constipados se han precavi-

21 Disponemos de más de ciento cincuenta embargos para el siglo XVIII, sacados del AGI, en las secciones de Santo Domingo, núms. 543, 561, 572 B, 2295, 2296, 2300, 2305, 2314, 2358, 2360, 2367, 2377 y 2414; y en Escribanía de Cámara, núms. 120 A y B, 121, 126 A y B, 127 B y C, 128 A y B, 129 A, 130 A y C, 131 A, 132, 139 C, 140 B y C, y 142 A. Entre todos los embargos sólo hemos encontrado dos referencias a la cocina formando parte del inmueble. Una, se encontraba en la casa del gobernador Antonio de Robles y Silva. San Juan, 27 de octubre de 1700. Escribanía de Cámara, 126 B. Y la otra, en la de Pedro García Guerrero. Ponce, 29 de abril de 1700. AGI, Santo Domingo, 561. de 1791.

22 AGI, Santo Domingo, 2370. Antonio de Filangieri al conde de Lorena. Madrid, 24 de junio

23 AGI, Santo Domingo, 2396. Petición del procurador de la ciudad de San Juan en Madrid, Pedro de Leyseca, al rey. Madrid, 20 de marzo de 1776.

24 AGI, Santo Domingo, 2295. Juan Cintrón al gobernador Francisco Danío Granados. San Germán, 19 de abril de 1711.

25 AGI, Santo Domingo, 2396. Petición del procurador en Madrid de la ciudad de San Juan, Pedro de Leyseca, al rey. Madrid, 20 de marzo de 1776. 
do de muchas enfermedades, y en una palabra, este remedio es tan común en esta Isla que no hay mujer que no lo sepa ordenar." ${ }^{26}$

Al tratar de los vestidos mantendremos los mismos criterios que los utilizados cuando hemos hablado de los alimentos. No los vamos a estudiar bajo el prisma de la estética, ni analizar las telas con que se confeccionaban o estaban tejidos. Tampoco si unos y otros eran los más idóneos para el hábitat y clima en que se desenvolvían. Eso queda para otro estudio. Únicamente expondremos el proceso laboral que tenían que llevar a cabo las mujeres de Puerto Rico para transformar las fibras en telas y éstas en vestidos.

Lasierra afirmó que no hilaban, ni cosían, ni hacían medias: "cosen poco." Esto en parte era cierto, pero totalmente injusta la razón que esgrimió. En sus observaciones se vislumbra que la causa era la pereza, como si ellas no estuvieran dispuestas a cumplir con ese rol femenino. Existieron razones muy poderosas para considerar que su actitud en este asunto fue la más sensata.

La referencia que hizo sobre la poca aplicación de las puertorriqueñas al hilado de las fibras que producía la Isla es totalmente falsa. Durante el período hispano, existieron árboles de algodón en Puerto Rico. En casi todas las fincas los había y en algunas se llegaban a recolectar hasta dos cosechas: "Rara es la hacienda en que no se ven árboles de esta especie." En otro lugar escribió también Abbad: "Da dos cosechas al año, la de septiembre es más abundante que la del mes de marzo." ${ }^{27}$ Si la explotación para su venta en el exterior no comenzó hasta el último tercio del siglo $\mathrm{XVIII},{ }^{28}$ es preciso admitir que al menos hasta esas fechas los isleños hicieron uso de él para sus necesidades. Es incuestionable que no lo explotaron con regularidad desde el punto de vista económico hasta ese tiempo. Pero está comprobado que el algodón lo recolectaban para hilar y tejer y el sobrante lo comercializaban en el mercado extranjero, porque el español no lo demandaba. Paradójicamente, es el fraile benito el que nos ofrece la información al anotar: "Los extranjeros llevan lo que sobra después de hacer sus hamacas en que lo emplean.” ${ }^{\prime 29}$ En buena lógica cabe

26 AGI, Santo Domingo, 2504. Certificado del médico José Sabater. Puerto Rico, 21 de octubre de 1771 .

27 Abbad y Lasierra: Historia geográfica..., págs. 161 y 234. pág. 153 .

28 Gil Bermejo, Juana: Panorama histórico de la agricultura en Puerto Rico, Sevilla, 1970,

29 Abbad y Lasierra: Historia geográfica..., pág. 161. 
pensar que la mayoría de las isleñas sabían hilar, porque el algodón no se puede utilizar tal como lo produce el árbol. Hasta llegar a tejer una hamaca había que realizar un largo y penoso proceso, como despepitarlo a mano. Esta operación la efectuaban las mujeres. Sabemos que hasta 1792 no habían llegado a Puerto Rico las desmotadoras mecánicas. ${ }^{30}$ Una vez libre de la semilla se hilaba. Con este elemento cabían dos posibilidades. Una, tejer telas. Sin embargo, sus conocimientos en este arte no debieron ser notables, como se desprende de los escasos testimonios que poseemos para este siglo. Tan sólo hemos hallado en la documentación una noticia de la existencia, en 1710, de un telar, situado en San Germán. ${ }^{31}$ Otra posibilidad era tejer a mano: el ganchillo. Con este sistema se tejieron las hamacas, cuyo uso estuvo generalizado entre la población. La clase baja como único medio en el que descansar, y la alta, compartiéndola con la cama tradicional, ${ }^{32}$ perdurando esta realidad, al menos, hasta finales del siglo XIX.

"Cosen poco", afirmó Lasierra. Estaba en lo cierto. Expuesto así, induce a pensar que si no lo hacían era por desidia, por dejadez. La realidad histórica que le tocó vivir apunta hacia otra dirección. Sin duda, para coser hay que tener con qué. Durante el siglo XVIII la falta de tejidos fue motivo de una preocupación constante en todas las autoridades, tanto civiles como eclesiásticas. Tal hecho lo refleja la documentación con insistencia. A finales del siglo XVII el obispo Francisco de Padilla solicitó ropa hecha a la Corona

"porque así podrá vestir repetidamente estas criaturas y remediar otras muchas, especial las mujeres, cuyo desabrigo me consta es tanto que no sólo dejan por él de oír misa, pero en sus propias casas viven a puerta cerrada por lo que sé a la honestidad de su sexo." ${ }^{33}$

Su petición fue atendida, aunque lo enviado no concordaba con su solicitud. Le remitieron tejidos y no ropa confeccionada. Pese a ello, el prelado dio las gracias al rey de manera efusiva con estas palabras: "La llega-

30 AGI, Santo Domingo, 2311 y 2370. El gobernador interino, Francisco Torralbo, a Diego Gardoqui. Puerto Rico, 12 de diciembre de 1792. Abbad y Lasierra: Historia geográfica..., pág. 161.

31 AGI, Escribanía de Cámara, 128 B. Su propietario se llamaba Nicolás de Ayala.

32 Dumont, Enrique: Memoria sobre la historia médico y quirúrgica de las regiones intertropicales de América (Islas de Cuba y Puerto Rico, México, Santomas, Guayana...), La Habana, 1875. pág. 19.

33 AGI, Santo Domingo, 173. El obispo Francisco de Padilla al rey. Puerto Rico, 2 de febrero de 1688 . 
da del socorro causó tan grande alegría que no hay ponderación que pueda significarla...." ${ }^{34}$

Otro prelado, en 1750, después de la visita canónica a la Isla, comprobó que la falta de vestidos era de tal magnitud que algunas esclavas y mujeres pobres iban desnudas de cintura para arriba, por lo que ellas mismas se autoexcluían del precepto de la comunión por Pascua Florida. Conocedor de la situación real del país, entendió que la solución era difícil de resolver, por lo que determinó que aquellas circunstancias no debían ser un obstáculo para cumplir con lo que mandaba la Iglesia y así dispuso "que lleguen a tan santa unción con la mayor honestidad y decencia, cubriéndose los pechos con las manos." ${ }^{35}$

Constantemente se levantaron voces pidiendo soluciones para remediar tal situación. En una de las críticas que se hicieron a la Compañía de Barcelona se afirmaba que sólo introducía en Puerto Rico

"vinos, aguardientes y tejidos gruesos de algodón, que abominan hasta los esclavos de esta Isla, sin que se haya dedicado a surtirnos directamente ni aun de coletas, bramantes, creas, ruanes, bretañas, listados y otros géneros de indispensable consumo en todos los pobres, que constituyen notable exceso la mayor parte de estos habitantes." ${ }^{36}$

Tal estado de cosas lo refleja la existencia de un mercado de ropa de lance. Cualquier vestido usado se podía vender sin importar que hubiera pertenecido a un enfermo contagioso: siempre había un comprador. Las autoridades locales por razones de higiene lo prohibieron, pero sólo en los casos "de personas enfermas o desconocidas." ${ }^{37}$ Cuando se trataba de individuos cuya identidad era conocida, no se ponía inconveniente alguno. Su tráfico constituyó moneda común en el siglo XVIII..$^{38}$ de 1690.

34 AGI, Santo Domingo, 173. El obispo Francisco de Padilla al rey. Puerto Rico, 6 de mayo

35 AGI, Santo Domingo, 567. Edicto del obispo Julián de Antolino. Puerto Rico, 22 de noviembre de 1750 .

36 AGI, Santo Domingo, 2414. Junta de la real hacienda. Puerto Rico, 7 de agosto de 1793.

37 AGI, Santo Domingo, 554. En las Nuevas Ordenanzas de San Germán, datadas el 22 de abril de 1735, en el punto 25 se dice: "Que ninguna persona venda ropa hecha ya usada para evitar los males y enfermedades contagiosas, que por ellas se introducen como se ha experimentado, pena así al vendedor de dos ducados con aplicación de por mitad o tercia parte..., y la ropa se echará al fuego. Y se entiende esta ordenanza con la ropa de las personas desconocidas." AGI, Santo Domingo, 2360. En un informe del procurador general de San Juan, fechado en Puerto Rico, 12 de septiembre de 1752, se dispone que las ropas de los enfermos contagiosos deben "consumir el fuego, porque se experimenta que o se vende o se tira en lugares donde los pobres ignorantes del contagio las recogen para su socorro de que resulta apestarse."

38 AGI, Santo Domingo, 2396. Petición del procurador de la ciudad de San Juan en Madrid, Pedro de Leyseca, al rey. Madrid, 20 de marzo de 1776. 
A la vista de las citas expuestas, cabe preguntarse si la isleña no cosía por desidia o por que no tenía telas con qué hacerlo. Pensamos que por lo segundo. Con estas observaciones hemos intentado situar en su justo punto unas reflexiones realizadas muy a la ligera por informadores superficiales y en las que la puertorriqueña no queda bien parada. La mujer hiló, tejió y cosió siempre que tuvo necesidad de ello y las circunstancias se lo permitieron.

\section{Los oficios y la mujer}

\section{Modistas}

Conectando con lo anterior hay que afirmar, por tanto, que gran número de mujeres confeccionaban sus propios vestidos y los de su familia. Es cierto que el traje popular era muy simple y de pocas complicaciones. Los varones normalmente se cubrían con "una camisa y un calzón largo de lienzo listado de colores, un sombrero de paja y un sable que siempre llevan ceñido." El de las mujeres quedaba reducido "a una camiseta muy escotada y llena de pliegues, uno o dos pares sayas de lienzo pintado." Lasierra comprueba que a causa de esta forma de vestir "llevan los pechos, brazos y parte de la espalda descubiertos, manifestando su poca honestidad y recato." Intenta excusarlas, en parte, afirmando que a causa del clima no llevan "más vestido que el muy preciso para cubrir su desnudez." ${ }^{39}$

Para el cronista la causa de que el traje de los isleños fuera tan liviano tiene un componente determinista: el clima. ${ }^{40}$ Pensamos que no fue ésa la única motivación. A la comodidad había que añadir, al menos, una causa más: la falta endémica de tejidos. Clima y escasez de telas originaron el traje popular.

La participación de las elites fue mínima en su creación. Concretamente los "hombres de honor", aquéllos que detentaban cargos concejiles,

39 Abbad y Lasierra: "Viaje a ...”, s/n. En el Boletín Histórico de Puerto Rico, vol. VI, pág. 222, el obispo Manuel Jiménez Pérez, después de realizar la visita canónica a Puerto Rico, en su afán de corregir la deshonestidad que suponía el uso escueto de la tela y lo generoso en mostrar sus encantos las mujeres, nos hace una descripción del vestido muy parecida a la de Abbad. Dice así: "Se ha notado no sin intenso dolor de su corazón el abominable traje y uso deshonesto con que nuestras mujeres se atreven a andar por las calles públicas y entrar en las iglesias, llevado las sayas tan sumamente cortas y los pechos tan descubiertos, que no sólo escandalizan, sino, que al mismo tiempo, son causa de muchos y graves pecados."

40 Abbad y Lasierra: "Viaje a...”, s/n. 
debían vestir con decencia. Un alguacil fue acusado "porque su villanía indecencia lo indicaba, pues ni una capa cubría lo grosero de su cuerpo." ${ }^{41}$

Los capitulares de San Germán fueron tachados de utilizar siempre los mismos trajes negros. Tal indumentaria estaba destinada únicamente a los lutos personales y para los miembros de la casa real. Un edil alegó en su defensa:

"Que como escasamente se puede tener un vestido decente, éste se hace de negro y así lo utilizan a diario y en las ocasiones que se precisa."

\section{Otro pretextó:}

“... que estos géneros de vestuarios no se traen tan sólamente por fúnebres vestiduras, ni sólo por continua gala por ser de las que con más frecuencia se usa en esta referida villa..." ${ }^{42}$

Las puertorriqueñas de las clases altas tampoco usaban los trajes populares. Vestían a la moda europea. A título de ejemplos trascribiremos literalmente algunas de las ropas que utilizaban: "Unas sayas de tafetán doble negro con su casaca de lo mismo"; "unas enaguas de tafetán rosado"; "un capotillo de grana de mujer con guarnición de oro"; "dos sayas de mujer, una de seda de la China y otra de bayeta" ${ }_{43}$; "dos camisas de mujer labradas y guarnecidas de encajes" necida de galón de oro"; "una casaquita de brocado rosado, guarnecida de oro y botones cubiertos de oro y hormillas de palo"; "dos camisas de mujer, una blanca y otra de seda rosada, guarnecida de encajes..." 45

Así se puede comprobar que el grupo dirigente de Puerto Rico vestía de espaldas a la realidad geográfica. Su atuendo estaba acorde con la moda de allende los mares y pocos eran los puntos comunes con el traje popular.

41 AGI, Santo Domingo, 2360. Informe de los presbíteros Silvestre Echevarría y José Ximénez. Puerto Rico, 15 de octubre de 1778.

42 AGI, Escribanía de Cámara, 130 B.Cargos y descargos de los miembros del cabildo de San Germán. San Germán, 4 de marzo de 1735.

43 AGI, Escribanía de Cámara, 127 B. Embargo de los bienes de los hijos del gobernador Juan Fernández Franco de Medina. Puerto Rico, 19 de octubre de 1706.

44 AGI, Escribanía de Cámara, 141 C. Embargo de los bienes de José González. Puerto Rico, 5 de julio de 1725 .

45 AGI, Escribanía de Cámara, 141 C. Embargo de los bienes de Nicolás de Castro. Puerto Rico, 6 de julio de 1725 . 
Lo mismo que la isleña cosió la ropa sencilla, también confeccionó la más delicada. Los testimonios directos son escasos, tan sólo poseemos uno. El sargento mayor, José de Andino, retuvo a unos soldados cuarenta pesos para entregarles a cambio ropa. Los interesados le rogaron que "se la diese sin hacer porque ellos tenían a sus mujeres que lo coserían sin gastar en sus hechuras y no quiso." Las prendas entregadas fueron una casaca de picote forrado de holandilla, chupa de listado, calzón de droguete y dos camisas de ruán. ${ }^{46}$

Sin embargo, existe una abundante documentación que nos manifiesta bien a las claras que había otras mujeres, que podemos considerarlas como auténticas modistas. Si ojeamos, aunque sea muy por encima, los diferentes embargos que de algunas tiendas se hicieron en el siglo XVIII, comprobamos que todas participaban de un común denominador: la ausencia de ropa confeccionada en sus anaqueles, quedando reducidos a la existencia de tejidos nobles, faltando casi por completo los que empleaba el pueblo en sus trajes como "el lienzo listado, cuyo consumo es casi general en ella." ${ }^{47}$

Los comercios contaban con abundantes telas finas y de lujo pese a no disponer de géneros para las hechuras de trajes populares. Así, encontramos holandillas azules, platillas, picotes de lana negra y morados, tafetanes dobles rosados y blancos, rasos y listados de China, rasos de España, gorgonas, barraganes, paños negros y encarnados, "bretaña angosta", ruán holandés y catalufas. ${ }^{48}$ La relación de estos tejidos únicamente la presentamos como un simple muestreo. En los embargos que se llevaron a cabo a particulares en esta centuria, en especial a toda clase de autoridades, aparecen otros tipos de telas de lujo.

Con estos tejidos se confeccionaron trajes muy sofisticados para hombre, cuya sola descripción nos indica que sus artífices debieron ser modistas consumadas. La escueta reseña que nos dejaron los individuos que inventariaron los bienes se comenta por sí misma. He aquí algunos ejemplos:

46 AGI, Escribanía de Cámara, 140 A. Declaración del soldado Juan García Chiclana. Puerto Rico, 9 de noviembre de 1721.

47 AGI. Santo Domingo, 2303. Representaciones del gobernador Juan Dabán y del tesorero Gabriel Gutiérrez al rey. Puerto Rico, 2 de octubre de 1783. Santo Domingo, 173. Un siglo antes el obispo Padilla solicitó al monarca telas para los pobres. Le decía: "El crudo es el género que tiene más consumo." Puerto Rico, 2 de febrero de 1688.

48 AGI, Escribanía de Cámara, 141 B. Embargos de los bienes del médico Juan Maissonet. Puerto Rico, 12 de julio de 1725. Y de Nicolás de Castro. Puerto Rico, 6 y 7 de julio de 1725. 
"Un vestido de raso labrado de color perla, forrado de tafetán doble rosado, con botones del mismo género, con chupa y calzón de raso encarnado con flores de oro y plata y forrado en tafetán encarnado y botones de hilo de oro."

\section{Otro:}

"Un vestido de carro de color azul nuevo con botonadura de plata y presillas de lo mismo, forrado en raso pajizo guarnecidas con guarnición de plata con botonaduras de lo mismo y calzón del mismo raso." ${ }^{49}$

Algunos tasadores fueron más sobrios en su exposición, pero a pesar de ello se intuye la riqueza de los ropajes como "una casaca de cordoncillo de seda forrada de tafetán azul", o "de raso negro labrado, forradas de tafetán negro", o "un par de calzones de lama rosada", o "una chupa de raso verde", etc....

A esta realidad se le puede objetar que dichos trajes no se hicieran en Puerto Rico, sino que sus dueños los trajeran cuando llegaron destinados a la Isla. Hay que aceptar esta hipótesis, al igual que algunos individuos de un nivel económico alto lo encargaran al extranjero, concretamente a Santo Tomás. ${ }^{51}$

Asimismo, hubo otros que en vez de solicitar trajes confeccionados, encargaron tejidos nobles, como Miguel Enríquez, que pidió le remitieran

"un corte de vestido de color perla o de color ámbar, sea droguete, sea de paño, con dos pares de calzones de lo propio y los forros sean de brin del color que se hallare más adecuado y seda para los ojales correspondientes."

También demandó "un corte de chupa y calzón de raso negro adamascado doble." ${ }^{2} \mathrm{Si}$ se solicitan telas era porque existían modistas con los conocimientos pertinentes para transformarlas en trajes. Se cuenta con otra prueba determinante. En las fiestas que se realizaron para la exaltación al

49 AGI, Escribanía de Cámara, 140 B. Embargo de los bienes del gobernador Gabriel Gutiérrez de la Riva. Puerto Rico, 30 de julio de 1703.

50 AGI, Escribanía de Cámara, 140 A. Embargo de los bienes del contador Jerónimo Narro. Puerto Rico, 17 de noviembre de 1707.

51 AGI, Escribanía de Cámara, 138 B. Importe de varios tejidos comprados en Santo Tomás. Santo Tomás, 19 de junio de 1715. El gobernador Juan de Ribera encargó que le trajeran de Santo Tomás: "Dos vestidos. Uno, de escarlata con su calzón, todo galoneado y con botones de oro. Otro, de lluvia de plata con sus calzones galoneados de plata y botones de lo mismo. Una camisa de brocado con sus franjas, dos pares de medias y un sombrero." abril de 1715 .

52 AGI, Escribanía de Cámara, 142 A. Miguel Enríquez a Santiago Giblens. Puerto Rico, 7 de 
trono de Fernando VI, dice el cronista anónimo que "cuatro riquísimos vestidos previno nuestro señor gobernador para quitarse el luto de su rey y nuestro." La palabra previno pudiera originar sospechas y hacer alusión a preparar más que a confeccionar. Salimos de dudas cuando más adelante en el informe se nos dice que

"singularizose nuestro general (gobernador) en un vestido que para ese día mandó hacer de una riquísima y apreciable talado oro guarnecido todo que llamamos los indianos punto de España."

En otra ocasión afirmó: “... para esa festividad mandó hacer un vestido de tisú de oro muy brillante cobre campo rojo....”33

En definitiva, se puede afirmar, sin ningún género de duda, que la profesión de modista constituyó un oficio muy cualificado en Puerto Rico, rayano casi en lo artístico. Pero estas artesanas u otras menos duchas también trabajaron por cuenta ajena en la confección de prendas de vestir menos complicadas, más simples, como calzones y camisas para los escla$\operatorname{vos}^{54} \mathrm{y}$ calzones, casacas y chupas para los soldados. ${ }^{55}$

Estas afirmaciones no empece lo que exponíamos más arriba sobre los conocimientos que casi todas las mujeres isleñas poseían sobre la costura. Las modistas cosían para personas que económicamente podían costear esos lujos o para esclavos y soldados que, por lo general, no tenían mujeres y dependían para tales casos de terceras personas.

\section{Panaderas}

El oficio de panadero se practicaba sólo en San Juan y en algunas poblaciones limítrofes. En el resto de los lugares de Puerto Rico no se consumía pan de trigo, sino ciertos sucedáneos como las tortas de casabe o los

53 Boletín Histórico de..., tomo V, págs. 148-193. "Relación verídica en la que se dan noticias de lo acaecido en la isla de Puerto Rico a fines del año de 45 y principios de el 47 con motivo de llorar la muerte de nuestro Rey y señor don Phelipe Quinto y celebrar la exaltación a la corona de nuestro señor y rey don Fernando Sexto. Dedícase al señor coronel de los reales ejércitos don Juan Joseph Colomo gobernador y capitán general de dicha isla. Por un afecto servidor, en 19 de febrero de 1747."

54 AGI, Santo Domingo, 567. Cuenta y relación jurada de Miguel Enríquez. Puerto Rico, 20 de diciembre de 1713. Escribanía de Cámara, 138 A. Libro de cuentas de Fernando de Castro. Puerto Rico, 12 de febrero de 1714.

55 AGI, Santo Domingo, 2310. Relación de lo que importaron las telas de los uniformes de las milicias. Puerto Rico, 28 de marzo de 1791. 
plátanos. ${ }^{56} \mathrm{El}$ pan de trigo constituyó un alimento casi exclusivo de la población blanca y de color pudiente y asentada en la zona metropolitana de la capital de la Isla. ${ }^{57}$

A la tropa se le acostumbraba a comer pan de casabe desde el primer momento que ponía los pies en suelo puertorriqueño. Tres días a la semana se les suministraba este alimento, que no repugnaba a sus paladares: ${ }^{58}$ "El pan puede decirse que no es un renglón de primera necesidad en un país donde está subrogado por otras muchas materias alimentarias..." 59

La ocupación de los tahoneros podía ser realizada indistintamente por hombres o por mujeres. En las Ordenanzas de San Juan de 1735 se disponía que los beneficios que obtuvieran del pan amasado debían ser de “... una moderada ganancia al panadero o panadera..." ${ }^{60}$ La sociedad había encomendado este rol tanto al varón como a la mujer. Sin embargo, el mismo año que se redactaron las citadas Ordenanzas sólo ejercían esta profesión las mujeres.$^{61}$ Con el avanzar de la centuria los hombres fueron imponiéndose en la profesión. En 1779 existían en la capital de la Isla nueve panaderos, siete varones y dos mujeres.$^{62}$ En 1788 su número siguió siendo

56 AGI, Santo Domingo, 2303. Del gobernador Juan Dabán a José de Gálvez. Puerto Rico, 20 de junio de 1782. El gobernador escribió: "El consumo actual de harinas de esta plaza incluida la poca que se extrae para los partidos circunvecinos, pues los más distantes comen casabe y plátanos o se privan de uno y otro."

57 AGI, Escribanía de Cámara, 141 A No hay que pensar que el pan de trigo lo consumía sólo el blanco por el hecho de serlo. El alférez Francisco Serrato fue comisionado por el gobernador Francisco Danío Granados para fundar el pueblo de Humacao con los emigrantes canarios recién llegados a Puerto Rico. Entre las primeras cosas que se le ordenó estaba "que pusiese un platanal para comodidad de todas ellas, por ser el fruto lo que sirve de pan en la Isla." Certificación del escribano Francisco de Sotres. Puerto Rico, 1 de noviembre de 1723.

58 AGI, Santo Domingo, 2350. Del gobernador Marcos de Vergara a Julián de Arriaga. Puerto Rico, 6 de diciembre de 1766.

59 AGI, Ultramar, 414. Proyecto para el establecimiento de un teatro en Puerto Rico. Puerto Rico, 1824. Para la construcción del teatro se puso una derrama de un maravedí por libra de pan. Se decía que tal medida afectaba a muy poca gente por su escaso consumo.

60 Catálogo de las cartas del cabildo de San Juan Bautista de Puerto Rico en el Archivo General de Indias. (Siglos XVI-XVIII), Recopilación y notas de José Joaquín del Real, San Juan de Puerto Rico, 1968, Apéndice II, págs. 284-291.

61 AGI, Santo Domingo, 547. Reconocimiento a las panaderías de San Juan. Puerto Rico, 30 de diciembre de 1735. Entre otras noticias informa: "El secretario de gobernación y hacienda con asistencia del ministro de vara Bernardino León pasaron a hacer reconocimiento de todas las casas de las panaderas de esta ciudad y otras particulares en donde por tiempo pasados se vendía pan, y habiéndolas registrado una en pos de otra no encontraron harina alguna, ni poca ni en mucha cantidad, a causa de responder igualmente dichas panaderas, que había más de seis meses se les había acabado, por cuya razón no amasaban."

62 Archivo Histórico Nacional (Madrid). Cuentas del ramo de multas. Puerto Rico, 5 de julio de 1788. En adelante, AHN, Consejo de Indias, 21469. 
nueve, tres y seis respectivamente. ${ }^{63} \mathrm{Y}$ en 1793 la participación femenina quedaba reducida a una tahonera: el resto lo componían hombres. ${ }^{64}$

No poseemos información sobre el proceso seguido hasta llegar al dominio de este oficio por parte de las puertorriqueñas y a la posterior abdicación en favor de los varones. Como hipótesis, y sólo como tal, cabe pensar que dichos menesteres constituyeron en España ocupaciones domésticas periódicas propias de las mujeres. Esta norma cultural pasó a América, y concretamente a Puerto Rico. La familia que poseía medios económicos suficientes amasaba su propio pan. Así comprobamos que el gobernador Alberto Bertolano entregaba harina dos o tres veces por semana a una pariente suya para que le cociese pan. Ella, aprovechándose de la situación y abusando de la confianza, amasaba más cantidad, que luego vendía por las calles de la ciudad ${ }^{65}$ Esta situación fue válida mientras la elite de la sociedad sanjuanera estuvo reducida a unas pocas familias con una estructura social muy elemental y descapitalizada.

Aunque en las primeras Ordenanzas de San Juan de 1627 ya se hace referencia indirecta a la profesión de panadero, no se manifiesta el sexo de quienes lo ejercían. No hay que olvidar que además de las "familias principales", consumidoras naturales de pan de trigo, desde finales del siglo XVI existieron en Puerto Rico varias compañías de soldados profesionales, en su mayoría peninsulares, en cuya dieta dicho alimento era básico y por su ocupación no disponían de tiempo para elaborarlo. Como una prolongación de la faena doméstica, es muy posible que algunas isleñas amasasen para ese mercado que lo demandaba. Y así continuaron dominando la profesión hasta mediados del siglo XVIII, cuando se produjeron las reformas de Carlos III. Los cambios en el orden militar supusieron la llegada de más tropa y, por ende, de nuevos consumidores de pan. ${ }^{66}$

A partir de esos momentos, y hasta el final de la centuria, pasaron por la Isla los regimientos de León, Toledo, Victoria, La Corona, Bruselas, Nápoles, Cantabria y África con un total de más de ocho mil hombres. ${ }^{67}$

63 AGI, Santo Domingo, 2367. Proposición de los panaderos de San Juan al gobernador Juan Dabán. Puerto Rico, 28 de enero de 1788.

64 AGI, Santo Domingo, 2413. Relación de los panaderos de San Juan. Puerto Rico, 18 de noviembre de 1793 .

65 AGI, Escribanía de Cámara, 129 A.

66 Torres Ramírez, Bibiano: La isla de Puerto Rico (1765-1800), San Juan de Puerto Rico, 1968, págs. 173-211.

67 Marchena Fernández, Juan: Oficiales y soldados en el ejército de América, Sevilla, 1983, págs. 56-58. 
Y si a esto unimos el aumento de la población blanca, que paulatinamente mejoró su nivel de vida, la demanda desbordó la capacidad económica de las mujeres panaderas. Ya no bastaba preparar unas pocas piezas: había que amasar para muchas personas. Se había pasado de un oficio artesanal a una pequeña industria. No obstante, bastantes particulares continuaron cociendo su propio pan. ${ }^{68}$

También puede confirmar esta teoría el origen social de las panaderas. Por las razones antes expuestas no pertenecían a la clase privilegiada. La documentación es muy parca a la hora de indicar su procedencia social. En una sola de las relaciones de los panaderos, la de 1788, se nos ofrecen algunos datos, pero no de todas. Eusebia de la Torre era mulata; María de la Concepción Beltrán, viuda; María del Carmen, abuela con varios nietos que alimentar, y otra, que no se dice su nombre, mujer de Matías Suazo. ${ }^{69}$ En la de 1793 la única mujer que aún permanecía en el oficio era, junto con un hombre, la que menos harina amasaba: un barril diario. ${ }^{70}$

Al margen de estas hipótesis, es a partir de entonces cuando al analizar las fuentes para la historia de Puerto Rico surge casi de repente y de forma abrumadora el problema de la escasez de harinas. Hasta ese momento, aunque se hace referencia a él, no lo muestran como algo fundamental. ${ }^{71}$

\section{Lavanderas}

El lavado de la ropa en Puerto Rico tuvo dos inconvenientes. Uno, específico de San Juan: las periódicas faltas de agua dentro de las propias casas. Otro, general para toda la Isla: la endémica escasez de jabón.

68 AGI, Santo Domingo, 2367. Informe del síndico de San Juan, Antonio de Córdova. Puerto Rico, 28 de agosto de 1796.

69 AGI, Santo Domingo, 2367. Proposición de los panaderos de San Juan al gobernador Juan Dabán. Puerto Rico, 28 de enero de 1788.

70 Ibídem.

71 AGI, Santo Domingo, 539, 547, 544, 2289 y 2300. Desde el principio del siglo XVIII hasta 1765 hemos encontrado ocho documentos que hacen referencia al problema de las harinas. Desde las reformas de Alejandro O'Reilly hasta el final de la centuria las fuentes sobre este particular son abrumadoras. Para el estudio del abastecimiento, necesidades y consumición contamos con setenta y dos documentos en las secciones de Santo Domingo, núms. 2300, 2301, 2363, 2367, 2369, 2370, 2413, 2414, 2484 y 2491. En Ultramar, núms. 451 y 479. Y en Indiferente General, 1907. Este hecho es, asimismo, evidente en Las actas del cabildo de San Juan de Puerto Rico. Mientras que hasta 1765 únicamente aparecen nueve referencias sobre el problema de las harinas, a partir de ese año se elevan a veintidós. 
En la capital muchas viviendas poseían aljibes con el fin de recoger las aguas de lluvia, que empleaban básicamente para beber y los usos domésticos..$^{72}$ Los que no poseían agua propia se abastecían de una fuente, la llamada de San Antonio, que el gobernador Sancho de Ochoa mandó hacer junto a la Fortaleza, aprovechando un manantial que por allí fluía. ${ }^{73}$

San Juan, asimismo, contaba con aljibes públicos. Bajo el patio del Morro, O'Reilly hizo construir un gran depósito para almacenar agua, que podía abastecer a cinco mil personas durante tres meses. Con ello se pretendía hacer frente a un futuro asedio enemigo, al tiempo que se evitaba el gasto diario que ocasionaba el transporte de agua en barcas para el uso de la tropa. ${ }^{74}$ Entre los pozos comunes se encontraban el del Tejar ${ }^{75}$ y el que estaba junto a la sacristía de la catedral. ${ }^{76}$

El abastecimiento de agua a la capital de la Isla fue motivo de preocupación tanto para las autoridades militares, ${ }^{77}$ como para las municipales. Cuando el período de la seca estaba próximo, los capitulares procuraban arreglar y adecentar la única fuente: la de San Antonio. ${ }^{78}$ También era la ocasión de recordar a los particulares, que tenían aljibes propios, que debían tenerlos preparados y limpios para cuando se acercara la época de las lluvias, con el fin de que "no se experimenten las faltas de agua que todos los años se padecen por muy poca que sea la seca." 79

Este problema era genuino de San Juan. Por la dispersión geográfica de su población, el resto de la Isla no tuvo este problema. ${ }^{80}$ Prácticamente todas las viviendas se encontraban diseminadas a lo largo de los ríos y arroyos, de lo cuales no sólo obtenían el agua que precisaban para sus necesidades vitales, sino que también encontraban en ellos un complemento a su dieta con la pesca. ${ }^{81}$

72 Abbad y Lasierra: "Viajes a...", s/n.

73 AGI, Santo Domingo, 174. El cabildo eclesiástico al rey. Puerto Rico, 26 de octubre de 1605.

74 Torres Ramírez, Bibiano: "El mariscal O'Reilly y las defensas de San Juan, 1765-1777", Revista Historia, tomo IV, núm. 1, San Juan de Puerto Rico, 1954, pág. 15.

75 Actas del cabildo de San Juan... Tomo 1767-1771, Sección de 16 de agosto de 1770. de 1779.

76 AGI, Santo Domingo, 2363. Acuerdo del cabildo eclesiástico. Puerto Rico, 16 de octubre

77 AGI, Santo Domingo, 548. El gobernador Juan José Colomo al rey. Puerto Rico, 22 de septiembre de 1746. Santo Domingo, 2505. El gobernador Miguel de Muesas a Julián de Arriaga. Puerto Rico, 19 de mayo de 1775.

78 Actas del cabildo de San Juan... Tomos 1730-1750; 1751-1760; 1761-1767; 1785-1789, y $1792-1798$.

79 Actas del cabildo de San Juan... Tomo 1730-1750, Sección de 7 de enero de 1733.

80 López Cantos, Ángel: "Nivel de instrucción de Puerto Rico en los siglos XVI al XVIII", Revista de Historia, núm. 3, San Juan de Puerto Rico, enero-junio de 1986, págs. 79-90.

81 Abbad y Lasierra: "Viaje a...", s/n. 
La escasez de jabón afectó a toda la Isla. Por lo general era un producto casero, que fabricaban las mujeres, aprovechando los sebos y mantecas de los animales que sacrificaban. Pese a ser la carne uno de los alimentos que consumían con más asiduidad y abundancia, siempre hubo en Puerto Rico falta de materias grasas ya que su uso era múltiple. No sólo se empleaban en conseguir jabón, también en velas y aceites para alumbrarse y, principalmente, como un sucedáneo del aceite para condimentar las comidas. En ciertas ocasiones la penuria llegó a ser tan angustiosa que algunos gobernadores se vieron en la precisión de solicitar a las "islas extranjeras amigas" sebo, jabón y velas. ${ }^{82}$

Las ropas las lavaban las mujeres en las fuentes y riachuelos próximos a sus viviendas. Las capitalinas en sus propias casas si poseían aljibe y mientras contenía agua. Cuando llegaba el período seco y el agua se había agotado, acudían como las restantes mujeres a las fuentes y arroyos cercanos. Junto a la de San Antonio se construyó un lavadero público. En los meses de sequía se quedaba pequeño por el mayor número de lavanderas y entonces los aledaños cercanos al manantial se convertían en una prolongación del lavadero. El concurso era tan numeroso que el dueño de los terrenos colindantes se quejó al cabildo y llegó a solicitar que las que fueran a lavar allí le pagaran cierta cantidad por los perjuicios que recibía su hacienda por la gran cantidad de aguas jabonosas que entraban en sus tierras. ${ }^{83} \mathrm{El}$ ayuntamiento le contestó

"que no ha lugar la solicitud, y en caso de recibir algún perjuicio en sus terrenos se le reserva sus derechos para que los repitiese ante el tribunal o tribunales que correspondiese. ${ }{ }^{84}$

Las "familias principales" contaban con lavanderas en sus propias casas: las esclavas o criadas. Las mujeres de las clases bajas hacían ellas mismas sus coladas. Los mismos soldados no tenían empacho en lavar sus vestidos y uniformes, aunque fuera en lugares frecuentados por las mujeres. ${ }^{85}$

82 AGI, Santo Domingo, 2409. Real cédula al gobernador Miguel de Muesas. Madrid, 3 de septiembre de 1773.

83 Actas del cabildo de San Juan... Tomo 1781-1785, Sección de 5 de mayo de 1783.

84 Ibídem, Sección de 30 de junio de 1783.

85 Actas del cabildo de San Juan... Tomo 1767-1771. Sección de 16 de agosto de 1770. El procurador general del cabildo expuso, "que los soldados lavan en la pileta del Pozo del Tejar y echan a perder el agua." El cabildo solicitó al gobernador Miguel de Muesas que tomara las medidas pertinentes. 
No obstante, y pese a la escasez de noticias existentes sobre este particular, se puede afirmar que se dio el oficio de lavandera por cuenta ajena: aquéllas que cobraban una cantidad ya estipulada a terceras personas por sus servicios. El gobernador Danío Granados pagaba cierta suma de reales a la negra María de la Concepción cada vez que lavaba su ropa y la de su familia. ${ }^{86} \mathrm{Y}$ en el hospital de la Concepción — donde no se podía admitir mujeres por muy enfermas que estuvieran al "no haber proporción ni sirvientes de ese sexo"-, sí hubo siempre una negra empleada tan sólo para lavar las ropas de cama y los vestidos de los hospitalizados. ${ }^{87}$

\section{Vendedoras}

\section{Tenderas y pulperas}

La profesión de tendero o pulpero fue considerada en Puerto Rico como privativa del hombre. En 1814 se legisló lo siguiente:

\footnotetext{
"Toda tienda, pulpería, etc... deberá tener mostrador que cierre y separe enteramente al vendedor y a la especie de compradores a fin de que ninguna persona pase de él para dentro y el que pasare el mostrador si fuere hombre pagará junto con el pulpero o tendero que lo consienta cuatro pesos cada uno; y SIENDO MUJER SE EXIGIRA OCHO SOLO AL VENDEDOR, [en mayúsculas en el texto] quien sufrirá además la multa de cincuenta pesos de hallarse dentro reunidas personas de ambos sexos..." ${ }^{88}$
}

Sin entrar en las normas de índole moral, referentes a las relaciones de la pareja, lo que interesa aquí resaltar es la afirmación rotunda e inequívoca que se desprende de la disposición legal. Únicamente se hace referencia al tendero o pulpero, pero no como nombres genéricos, sino que se refiere a los individuos del género masculino, porque en la casuística posible del transgresor, la mujer no aparece como elemento culpable que permita pasar al otro lado del mostrador.

Esta afirmación se ve apoyada en cierta manera por las fuentes históricas consultadas. Sin embargo, hubo excepciones. La mujer ejerció de tendera, aunque en menor número que los varones, y sus establecimientos de 1726.

86 AGI, Escribanía de Cámara, 143. Simón Belenguer al rey. Puerto Rico, 9 de septiembre bre de 1805 .

87 AGI, Santo Domingo, 2377. El obispo Juan Alejo Arismendi al rey. Puerto Rico, 1 de octu88 AGI, Santo Domingo, 2297. Reglamento de policía. Puerto Rico, 1 de enero de 1814. 
estaban tan bien surtidos como los de aquéllos. De las distintas relaciones de tiendas embargadas, sólo disponemos de dos que pertenecieran a otras tantas isleñas y que ejercían como auténticas tenderas: Ana Carrasquilla y Ana Teresa, ambas viudas. ${ }^{89}$

Asimismo, conocemos la existencia de pulperas propietarias de sus establecimientos. Eran tres y mulatas. María de Chaves, protegida del gobernador Alberto Bertolano, que le enviaba a su pulpería "los barriles de harina para que se amasasen y vendiese la libra a dos reales, y cacao, manteca, aguardiente romo, azúcar y los demás frutos de la tierra." ${ }^{90}$ Las otras dos eran Faustina Félix y María Laurencia..$^{91}$

Los ejemplos expuestos son una prueba de que tal oficio también lo ejercían las mujeres y más a menudo de lo indicado por la casuística de que disponemos. No hay que olvidar que las muestras con que contamos nacen por transgresiones a alguna normativa. Es de suponer, por tanto, que hubo otras que actuaron de acuerdo con las leyes y de las que no nos han llegado noticias de su existencia.

\section{Verduleras}

Las mujeres de color libres tenían prácticamente acaparada la venta al por menor de los productos hortícolas, que se despachaban en los puestos de la plaza de San Juan. En esta ocupación estaban los hombres en franca minoría..$^{92}$ En los puestos se podía comercializar cualquier "fruto del país," estando sólo prohibido vender las bebidas alcohólicas. Las frutas y verduras se desembarcaban a diario en el puerto en "lanchas que bajaban por los ríos de la costa norte." ${ }^{93}$

Se desconoce el momento en el que aparecen las llamadas casillas en la plaza de la capital de la Isla, pero lo que sí se sabe es que nacieron antes de que su uso fuera reglamentado por el ayuntamiento. ${ }^{94}$ La Plaza de las

89 AGI, Escribanía de Cámara, 126 B. Embargo de las tiendas de Ana Carrasquilla y Ana Teresa. Puerto Rico, 8 y 18 de octubre de 1700.

90 AGI, Escribanía de Cámara, 129 A. Cargos contra el gobernador Alberto Bertolano. Puerto Rico, 9 de febrero de 1721.

91 AHN, Consejo de Indias, 21469. Multas a Faustina Félix y María Laurencia. Puerto Rico, 3 de enero de 1777 y 31 de diciembre de 1782.

92 Actas del cabildo de San Juan... Tomo 1798-1803, Sección de 29 de marzo de 1802.

93 Ledru, Andrés-Pierre: Viaje a la Isla de Puerto Rico, San Juan de Puerto Rico, 1957, pág. 50.

94 Catálogo de cartas del cabildo de San Juan..., pág. 286. 
Verduras, como se la conocía, estaba situada en la misma plaza del cabildo. En un principio, las casillas se construyeron de forma anárquica: cada vendedora la plantaba donde más le convenía. Con el tiempo, el ayuntamiento se hizo cargo de ellas y de su conservación a cambio de unos aranceles. Al principio se subastaron y después se fijó una cantidad concreta, que era bastante alta, según el criterio de las verduleras. En 1777 el cabildo tomó la determinación de tirar todos los puestos de tablas y lonas y edificar unos nuevos de mampostería y tejas, situados sólo en dos lados, los perpendiculares a la fachada del edificio del cabildo, con el fin de que estuviera expedita la entrada. Con el tiempo, el puesto de pescado que se encontraba en La Marina de San Justo fue trasladado allí para comodidad de los vecinos. Unos años más tarde se habilitó una casilla para la venta de pan. No sólo comerciaban en la plaza las que tenían las concesiones de los puestos: había otras vendedoras ocasionales que les hacían la competencia, las llamadas "viandaderas silvestres que les impedían la venta por ponerse frente a las dichas a hacer las suyas." Lucharon contra el intrusismo que atentaba a sus intereses y consiguieron impedir "los tendajos". ${ }^{95}$

\section{Ambulantes}

Desde el principio del XVIII era frecuente oír la voz del quincallero por las calles de San Juan pregonando los géneros que acababan de llegar de España ${ }^{96} \mathrm{o}$ los "efectos de corso" apresados a los traficantes extranjeros. ${ }^{97}$

Los vendedores ambulantes de alimentos no aparecen en San Juan hasta finales del siglo XVIII. En esos años, y a principio de la centuria siguiente, se produce una auténtica eclosión en esta modalidad comercial hasta el extremo de convertirse en un serio competidor del comercio establecido en la Plaza de las Verduras y el de las mismas pulperías, circunstancia que obligó a los tenderos a quejarse ante las autoridades. Éstas, tras

95 Esta reconstrucción de la Plaza de las Verduras se ha hecho con las Actas del cabildo de San Juan..., tomo 1767-1771, sección de 22 de febrero de 1768; tomo 1777-1781, secciones de 13 de marzo de 1775 , de 28 de junio de 1777 , de 11 de mayo de 1779 , de 13 de marzo, de 29 mayo y 13 de noviembre de 1780; tomo 1781-1785, sección de 2 de julio de 1881; tomo 1785-1789, secciones de 25 de abril de 1785 , de 23 de octubre de 1786 y de 5 de mayo de 1788, y tomo 1793-1797, sección de 16 de octubre de 1797. de 1726.

96 AGI, Escribanía de Cámara, 143. Simón Belenguer al rey. Puerto Rico, 9 de septiembre

97 AGI, Santo Domingo, 561. El deán Martín Calderón al rey. Puerto Rico, 29 de septiembre de 1701. 
estudiar las denuncias, comprendieron la dificultad que entrañaba impedir esta forma comercial, pues estaba ya muy arraigada. Del posible veto se pasó a su reglamentación ya que una comisión vigilaría a los vendedores callejeros, al tiempo que les cobraría cierta cantidad de dinero en concepto de arbitrios municipales. ${ }^{98}$

Esta profesión se dedicó, al igual que la anterior, a comercializar los "frutos de la tierra." También estuvo monopolizada por las mujeres de color, pero con una nota diferenciadora: mientras aquéllas pertenecían al grupo de las mujeres libres, las ambulantes eran en su mayoría esclavas. Sin embargo, al margen de su situación social, constituyeron un grupo de trabajadoras por cuenta ajena y en beneficio de sus dueños. A esta situación se había llegado pese a la prohibición de que los siervos trabajaran para quienes no fueran sus dueños. El Reglamento de Policía de 1814 ordenaba taxativamente a este respecto que no "se destinen a vender comestibles u otros efectos por las calles negras o mulatas jóvenes y menores de treinta años y los amos que contravinieren a esta disposición se les obligará a que vendan dichas esclavas por su justa tasación." Las razones que el legislador esgrime para tal prohibición son de índole moral. En un artículo anterior se dice otro tanto de los esclavos varones que trabajaban diariamente para proporcionar un jornal a sus dueños. El dinero que obtenían el sábado era para su alimentación semanal, por lo que "se dedican — los hombres - al robo y otros vicios y las mujeres se prostituyen con el mayor escándalo.”99

\section{Maestras}

La profesión de maestras de niñas no aparece en la documentación hasta el final del siglo XVIII. Ignoramos en qué se basó Ledru para escribir: "En vano buscaría el viajero manufacturas o colegios..., el pueblo yace en la más completa ignorancia, los frailes y algunas mujeres enseñan un corto número de elementos de religión y gramática y las séptimas décimas partes de la población de la Isla no saben leer." Esta afirmación no refleja la realidad que muestran las fuentes históricas. Al margen de la aseveración final, hasta 1799 no hay alusión alguna al oficio de maestra, mientras que las referencias al maestro fueron constantes a lo largo del siglo. Basta oje-

98 Gaceta del Gobierno de Puerto Rico, San Juan, sábado, 28 de mayo de 1825.

99 AGI, Escribanía de Cámara, 143. Simón Belenguer al rey. Puerto Rico, 9 de septiembre de 1726 . 
ar las Actas del cabildo de San Juan de Puerto Rico. Desde 1739 las menciones a los maestros que solicitaban dar clase o que les pagasen sus emolumentos, entre otras referencias, fueron continuas

Las primeras noticias datadas sobre la profesión de maestras nacen en una sección del cabildo de San Juan el 25 de noviembre de 1799, en la que se trata de estudiar un proyecto para crear cuatro escuelas de niñas. Para ello se encargó a un capitular "informarse bien de las cuatro maestras que por sus buenas cualidades morales y políticas puedan desempeñar asuntos tan importantes." Pocos días después, el 12 de diciembre de aquel mismo año, el ayuntamiento podía contar con las maestras que precisaba, cuyos nombres eran: Paula Molinero, Juana Polanco, Josefa Echevarría y María Dolores Araujo.

Produce extrañeza que en el corto tiempo de siete días se hubiera resuelto un problema bastante considerable y a simple vista de difícil solución, porque de no existir maestras que estuvieran ejerciendo su oficio, al menos en San Juan, la selección no hubiera sido tarea fácil. Una escuela se puede improvisar; el profesorado, no. Una profesión tan cualificada como la enseñanza precisa años de preparación y formación. Ante esta realidad, no cabe otra explicación que deducir que la mujer puertorriqueña se dedicó al magisterio mucho antes que apareciesen referencias en la documentación. Desconocemos en qué momento de la historia de Puerto Rico una isleña montó una escuela, pero sin duda fue antes de lo señalado por las fuentes. ${ }^{100}$

100 López Cantos: “Nivel de instrucción en Puerto Rico...”, págs. 79-90. 